\title{
Jens-Ulrich Davids: Frankensteins Erben. Ein Theaterroman in fünf Akten.
}

\author{
Verlag Atelier im Bauernhaus, Fischerhude, 2012, 328 Seiten, \\ ISBN 978-3-88132-341-3
}

\section{Stefanie Beckmann}

Welche Funktion sollen Dichtung und Drama erfüllen? Sollen und wollen Dichter, wie Horaz in seiner „ars poetica“ sagt, entweder erfreuen oder nützen - aut prodesse volunt aut delectare poetae? Diese Fragen werden vom Protagonisten zu Beginn des Romans aufgeworfen. Romanheld Perikles Krause, kurz Peh genannt, und der Autor Jens-Ulrich Davids machen sich auf den Weg, sie in in 5 Akten und 24 Kapiteln zu beantworten.

Perikles Krause, 44, ein bisher unambitionierter, sich von Vertrag zu Vertrag hangelnder Germanistikdozent an der Carl von Ossietzky-Universität Oldenburg, erhält im Wintersemester 1999/2000 die Chance auf eine Juniorprofessur im neu aufzubauenden Lehrstuhl Darstellendes Spiel. Allerdings muss er „weitergehende Beweise künstlerischer Kompetenz" (15) erbringen. Peh soll mit einer Gruppe Studenten ein Theaterstück inszenieren, das folgende Forderungen erfüllt:

Es sollte von einer Gruppe, von Ihrer Theatergruppe, gemeinsam verfasst werden. [...] Es sollte ein aktuelles Thema sein, eine zeitgenössische große Frage sollte hinter allem stehen. [...] Dramatisierung eines Romans, [...] Gattungsüberblendung, Grenzauflösung, semantische Kontinuität; Tiefe und Vielfalt, Tradition und Modernität, denken Sie an Sokrates, denken Sie an Sloterdijk; eine große Künstlerin im Mittelpunkt; englischer Realismus als Vorbild, [... ] historische und designerisch aufregende Kostüme; aufbauend und vorwärtstreibend, Universitätsorchester berücksichtigen, [...] das Wort, das Wort, Weltwissen und religiöse Erfahrung; auf jeden Fall Aktualität und naturwissenschaftliche Präzision... (16).

Hiermit wird dem Regisseur Peh - und auch dem Leser - ein weites Feld eröffnet, in das Davids kenntnisreich im Verlaufe des Romans anregende Ausflüge in die Theatergeschichte und bildende Kunst sowie Diskussionen überTheatertheorien sät, die notwendig für das Verstehen der Charaktere und die Entwicklung des zentralen Konflikts sind. Davids Debüt ist in der Tat ein Theaterroman. Es lohnt sich durchaus, im Roman genannte Begriffe, Personen, Theater- und Filmproduktionen oder Kunstwerke an anderer Stelle nachzuschlagen, auch weil nötige oder ergänzende oder schlichtweg interessante Wissensbereiche 
wie z.B. Artauds Theater der Grausamkeit nur verkürzt diskutiert oder Gemälde wie „An Experiment on a Bird in the Airpump“ nicht gezeigt werden (können).

Angeregt durch seinen Freund Ronald, Gymnasiallehrer und Dialektiker, Vieltrinker und Vielphilosophierer, beschließt Peh, Mary Shelleys Roman „Frankenstein oder der moderne Prometheus" zu dramatisieren. Dieser wegweisende und vielfach inszenierte Stoff, in dem sich das Experiment gegen seinen Schöpfer wendet, scheint Peh eine spannende und lohnende Regieaufgabe zu sein, die ihn tatsächlich aber zunehmend überfordert - noch zwei Wochen vor der Premiere fehlen Bühnenbild und Schluss des Stückes - und deren Ergebnis er trotz Warnungen und Vorahnungen nicht absehen kann. Deutlich ist die Analogie zwischen dem Roman und dem Roman im Roman, aber auch Anlehnungen an Fellinis $8^{1 / 2}$ können hier in Inhalt und Form entdeckt werden.

Antiheld Peh, grüblerisch, zweiflerisch, selbstmitleidig, im Führungsstil antiautoritär und in seiner Rolle als Theaterleiter schwach, trifft auf eine Gruppe Studenten, die unterschiedlicher kaum sein kann und in der Realität zum Glück - wohl so auch nicht zu finden ist. Vor allem sind Folgende zu nennen: Tamar, in die sich Peh verliebt, sägt mit ihrem „Lebenstheater“ (294) an seinen und an des Lesers Nerven, Landpomeranze Anna erklärt den Naturbegriff, in dem sie Ziegen vom elterlichen Hof in die Aula treibt, und da ist Dauerstudent und Tamars Freund Anton, der selbst Tischfußball in Nietzescher Manier spielt und sich als apokalyptischer Rebell gefällt. Zunächst als verzogenes Blag daherkommend, wird er ein ernstzunehmender Gegenspieler Pehs, der ihn beharrlich fordert und in Frage stellt:

Die Kunst muss ins Leben, das Theater muss runter von der Bühne [...].“ (126). - „[Das Theater] kann weder belehren noch aufklären. [...] Dein ganzes Konzept ist falsch. (180).

$\mathrm{Zu}$ den sympathischeren Figuren gehören die besonnene, wenn auch lehrmeisterhafte Maja mit ihrem Arüflüw, dem Archiv für überflüssiges Wissen (noch in Papierform, nicht als Webseite), in dem sie gar nicht nur Unwissenswertes sammelt, und Lönsi, der Peh den Kopf zurecht rückt:

\footnotetext{
Und was hast du gemacht? Wie hast du sie unterstützt, angeleitet, inspiriert? Gar nicht. Du hast freundlich nachgefragt, du hast mal darauf verwiesen, dass da vieles zu sagen wäre, aber du hast nicht gesagt, was. Weißt du es nicht? Dann wehe uns. Oder hast du diese bekloppte pädagogische Idee, dass alles von den Studis erarbeitet werden müsste, von uns den Schauspielern?" (195).
}

Amüsant und anrührend lesen sich die telefonischen Scharmützel zwischen Peh und seinem Vater, der Gedichte schreibt und anlässlich seiner achtzigsten Geburtstagsfeier einen Menüentwurf zu Papier bringt, in der die Speisenfolge seine politische Entwicklung nachzeichnen soll.

Trotz Sabotage des Projekts von unterschiedlichen Seiten und Pehs Ringen um Orientierung, kommt die Adaption von Frankenstein tatsächlich zur Aufführung. Hier entwirft Davids, von der Muse arg geküsst, ein fantastisches, grün-goldenes Schlussspektakel, in welchem sich Frankensteins Erben offenbaren. 
Jens-Ulrich Davids, selbst Dozent an der Carl-von-Ossietzky-Universität Oldenburg im Fach Anglistik (British Studies) von 1974 bis 2005, nutzt autobiografisches Wissen über inneruniversitäre Querelen sowie seine langjährige Erfahrung als Begründer und Leiter der englischsprachigen, studentischen Sideway Theatre Company, mit der er rund ein Dutzend meist neuerer britischer und US-amerikanischer Stücke aufführte. Zusammen mit dieser Gruppe erarbeitete er eine Bühnenfassung von Shelleys Frankenstein, und in diesem Prozess entwickelten sich seine Ideen zum vorliegenden Roman. So gewinnt der Leser einen amüsanten Einblick in die Freuden und Mühen eines Theaterschaffenden - von obligatorischen Aufwärmübungen bis hin zur Finanzierung einer Produktion. Wer den Theaterleiter Davids kennt, wird ihn im Roman wiederfinden, z.B. als Passant in blauer Strickmütze oder in der Anleitung zur Übung Little Monsters. Und natürlich erheitert es ungemein, wenn die Gruppe nach der Probe in die Kneipe Tarock einfällt, wie die echten Studentengenerationen vor und nach ihnen. Davids beschreibt detailreich das Lokalkolorit zwischen Bremen und Dangast, so dass auch Leser, die die Region nicht kennen, eine Vorstellung universitären Lebens in und um Oldenburg erhalten. Der Roman ist nicht als Abrechnung eines ehemaligen Hochschullehrers, sondern eher als eine Hommage zu verstehen.

Neben demProbenprozess zu Frankenstein und den unterhaltsam-scheußlichen, von Peh schriftlich festgehaltenen Ergebnissen szenischer Improvisationen der Gruppe, nimmt Davids ebenfalls das aktuelle Geschehen der Jahre 1999 und 2000 in den Blick. Das Millenium und die damals einhergehende Beschwörung der Apokalypse, die Anfänge von Attac sowie Seitenhiebe auf den damaligen amerikanischen Präsidenten beleuchten den Zeitgeist und die Motivation der Charaktere. Inhaltlich hat der Roman also viel zu bieten, manchmal allerdings scheint er mit Nebenschauplätzen etwas überladen. Auch die Wechsel zwischen Pehs realem und surrealem Erleben erschließen sich nicht immer.

Leider sind (dem Lektor) einige formale Zinken unterlaufen, zu Beginn des dritten Akts fehlt der Titel des ersten Kapitels, nicht alle Seitenzahlen sind vorhanden, manchmal gibt es Rückfälle in die alte Rechtschreibung.

Davids schafft es in seinem Roman, auf unterhaltsame Weise zur Sprache zu bringen, was für das Leben zugleich angenehm und nützlich ist - entsprechend Horaz' dritter Intention: aut simuli et lucunda et idonea dicere vitae. ${ }^{1}$

\footnotetext{
${ }^{1}$ Quintus Horatius Flaccus: Ars Poetica. Die Dichtkunst, Lateinisch/Deutsch, übers. u. mit einem Nachwort versehen von Eckart Schäfer, 2. Aufl., Stuttgart 1984, S. 25.
} 